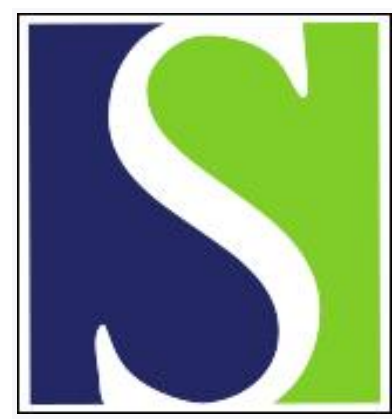

Scand J Work Environ Health 2015;41(1):75-83

https://doi.org/10.5271/sjweh.3450

Published online: 19 Aug 2014, Issue date: 01 Jan 2015

Association between ambient noise exposure, hearing acuity, and risk of acute occupational injury

by Cantley LF, Galusha D, Cullen MR, Dixon-Ernst C, Rabinowitz PM, Neitzel RL

The results of this study indicate that occupational noise exposures as low as 85 dBA may increase the risk of workplace injuries and that hearing impairment may be associated with increased risk of minor injuries. These findings suggest that occupational injury prevention programs may need to consider noise exposures as a preventable risk factor for injury.

Affiliation: University of Michigan, Department of Environmental Health Sciences, 1415 Washington Heights, 6611D SPH I, Ann Arbor MI 48109, USA. rneitzel@umich.edu

Key terms: acute occupational injury; ambient noise; association; exposure; hearing; hearing acuity; hearing loss; noise; noise exposure; workplace health; workplace safety

This article in PubMed: www.ncbi.nlm.nih.gov/pubmed/25137556

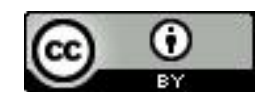




\title{
Association between ambient noise exposure, hearing acuity, and risk of acute occupational injury
}

\author{
by Linda F Cantley, MS, ${ }^{1}$ Deron Galusha, MS, ${ }^{1}$ Mark R Cullen, MD, ${ }^{2}$ Christine Dixon-Ernst, MS, MA, ${ }^{3}$ Peter \\ M Rabinowitz, MD, MPH, ${ }^{4}$ Richard L Neitzel, PhD, MS ${ }^{5}$
}

\begin{abstract}
Cantley LF, Galusha D, Cullen MR, Dixon-Ernst C, Rabinowitz PM, Neitzel RL. Association between ambient noise exposure, hearing acuity, and risk of acute occupational injury. Scand J Work Environ Health. 2015;41(1):75-83. doi:10.5271/sjweh.3450
\end{abstract}

Objective This study aimed to examine the associations between acute workplace injury risk, ambient noise exposure, and hearing acuity, adjusting for reported hearing protection use.

Methods In a cohort of 9220 aluminum manufacturing workers studied over six years (33 300 person-years, 13 323 person-jobs), multivariate mixed effects models were used to estimate relative risk (RR) of all injuries as well as serious injuries by noise exposure category and hearing threshold level (HTL) adjusting for recognized and potential confounders.

Results Compared to noise $<82 \mathrm{dBA}$, higher exposure was associated with elevated risk in a monotonic and statistically significant exposure-response pattern for all injuries and serious injuries with higher risk estimates observed for serious injuries [82-84.99 dBA: RR 1.26, 95\% confidence interval (95\% CI) $0.96-1.64 ; 85-87.99$ dBA: RR $1.39,95 \%$ CI $1.05-1.85 ; \geq 88$ dBA: RR $2.29,95 \%$ CI 1.52-3.47]. Hearing loss was associated with increased risk for all injuries, but was not a significant predictor of risk for the subset of more serious injuries. Compared to those without hearing loss, workers with HTL $\geq 25 \mathrm{~dB}$ had $21 \%$ increased all injury risk (RR 1.21, 95\% CI 1.09-1.33) while those with HTL 10-24.99 dB had 6\% increased risk (RR 1.06, 95\% CI 1.00-1.13). Reported hearing protection type did not predict injury risk.

Conclusion Noise exposure levels as low as 85 dBA may increase workplace injury risk. HTL was associated with increased risk for all, but not the subset of serious, injuries. Additional study is needed both to confirm the observed associations and explore causal pathways.

Key terms hearing loss; workplace health; workplace safety.

Noise exposure is ubiquitous in many occupational and non-occupational settings, with an estimated 22.4 million workers in the United States (US) exposed to hazardous noise on the job (1) and >100 million more exposed to potentially harmful ambient noise from traffic, personal listening devices, and other sources (2). Average noise exposures $>85 \mathrm{dBA}$ have been linked to a variety of adverse auditory and extra-auditory effects (3). Adverse auditory effects include temporary and permanent noise-induced hearing loss (NIHL) (4-6), which may interfere with on the job communication and impair workers' ability to hear warning signals or moni- tor workplace equipment (7). Current evidence suggests that $16 \%$ of adult-onset hearing loss globally is related to occupational noise exposure (8) and that hearing loss accounts for 4.2 million disability-adjusted life years (9). In the US, an estimated 10 million workers have NIHL resulting in hearing thresholds $\geq 25 \mathrm{~dB}$ (10), and such workers with hearing loss may work in environments where noise and hearing loss interact to impair ability to hear communications and other important safety signals $(7,11,12)$.

While NIHL is the classically-recognized health effect of noise exposure, mounting evidence links noise

1 Yale Occupational and Environmental Medicine Program, Yale University School of Medicine, New Haven, CT, USA.

2 Department of Internal Medicine, Stanford University School of Medicine, Stanford, CA, USA.

3 Alcoa Inc, Pittsburgh, PA, USA.

4 Department of Environmental and Occupational Health Sciences, University of Washington, Seattle, WA, USA.

5 Department of Environmental Health Sciences and Risk Science Center, University of Michigan, Ann Arbor, MI, USA.

Correspondence to: Richard Neitzel, PhD, University of Michigan, Department of Environmental Health Sciences, 1415 Washington Heights, 6611D SPH I, Ann Arbor MI 48109, USA. [E-mail: rneitzel@umich.edu] 
exposure to extra-auditory effects including increased stress (13), performance decrements $(14,15)$, reduced temporal processing skills (16), sleeping disorders (17), hypertension (18), and heart disease $(19,20)$. Some evidence suggests that adverse effects of occupational noise exposure can occur with exposures in the 80-84 dBA range $(21,22)$ - substantially lower than many current occupational noise exposure limits.

Occupational injuries also represent a significant burden globally, with an estimated 100 million occupational injuries occurring worldwide each year and evidence of under-reporting suggesting the actual number may be substantially higher $(23,24)$. During 2007 in the US alone, approximately 8559000 nonfatal occupational injuries occurred with associated costs totaling \$186 billion (24).

A number of studies have suggested an association between occupational noise and increased accident and injury risk $(6,25-28)$ and have proposed several possible mechanisms for such a link. Noise may cause distraction or impede concentration $(26,29)$, increase fatigue and prolong reaction time (30), and reduce ability to hear warnings signals or other critical auditory messages (7), each of which may contribute to accidents and injuries. Some have postulated that highfrequency noise exposure may disrupt the vestibular system increasing postural sway and position variability of center of pressure, which may increase risk for slips and falls particularly for those working at heights (31).

Noise exposure could also increase injury risk by causing hearing loss, which by itself could lead to increased accident risk $(25,26)$. Hearing difficulty resulting from overprotection due to use of hearing protection devices (HPD) in the workplace has also been suggested as a pathway for increased injury risk among HPD wearers (32). Workers wearing inappropriately protective HPD may experience decreased ability to hear, heed, or accurately interpret messages and workplace warning signals, and reduced ability to distinguish between sounds required to adequately monitor machines and other workplace equipment (7).

Other reports suggest that noise exposure may impair performance by interfering with information processing or influencing strategies for task completion (33), degrading working memory (34), or increasing the mental workload thus reducing cognitive resources available for task performance (35).

Although reports suggest that occupational noise exposure and hearing loss increase work-related accident and injury risk when considered independently (36, 37), relatively few reports have examined the combined effects of noise exposure and hearing loss on injury risk $(6,27,28)$. Furthermore, most have not adjusted for the possibility that noisier jobs could also be inherently more dangerous. The primary objective of this study was to examine simultaneously the association between ambient workplace noise exposure, hearing threshold level (HTL) and acute occupational injury risk among a cohort of aluminum manufacturing workers, adjusting for HPD type as well as job and individual level confounders known to increase injury risk in this worker population (38-40).

\section{Methods}

This cohort study included production and maintenance workers at six aluminum manufacturing plants in the US who contributed any active work time between 1 January 2003 and 31 December 2008. Aluminum manufacturing processes represented by these plants, all part of a single company, include a variety of highhazard activities such as smelting, fabricating, forging and casting. All data used for this study were available through an academic-corporate partnership between the company and Stanford and Yale universities initiated for the purpose of developing and implementing workplace safety and occupational health policies for the company. This study used six years (2003-2008) of data from separate linked datasets containing information on human resources, injury surveillance, industrial hygiene measurements, audiometric surveillance, and physical job demands. Each of these datasets is described below. Study protocols were reviewed and approved by the human subjects committees of Stanford University and Yale School of Medicine.

Using the human resources database, which has been described in previous reports $(38,39)$, we constructed job histories for each worker at the six study plants and calculated active person-time per year for each job held. Injury histories for each worker in each job held were constructed by year using the company's real time incident surveillance database, which contains information on work-related injuries and illnesses for all employees. Longstanding company policy mandates internal reporting of all incidents, including minor ones that require only first aid. In the incident database, injuries are described by a "nature of injury" variable, which was used to identify and retain for analysis acute injuries, including lacerations, contusions, dislocations, amputations, acute strains and sprains, burns, etc and "case type", which was used to distinguish minor injuries requiring only first aid from more serious injuries that resulted in medical treatment, restricted work, or lost work time. As is typical in occupational injury surveillance programs, no information was available regarding potential acoustic or auditory contributions to injury events; we assumed for the purposes of this analysis that acute injury events were the only types of injuries that might be affected by acoustic or auditory factors. All acute injury events for each person-job-year occurring 
between 1 January 2003 and 31 December 2008 were included for analysis. Separate analysis was conducted for the subset of serious injuries, ie, those that resulted in medical treatment, restricted work, or lost work time.

Noise exposure data were obtained from the company's industrial hygiene exposure assessment database. Because the company's industrial hygiene standard requires routine noise sampling for all jobs for which exposures ever equal or exceed an 8-hour time-weighted average of $82 \mathrm{dBA}$, the database contains multiple personal noise samples for individual jobs. We used these personal noise samples, collected over the work shift and representing $\geq 70 \%$ of shift length, to establish an average noise exposure for each job. By use of a process previously described (38), job titles were standardized to enable linkage of exposure information collected by job title to the individual workers exposed. Occupational noise exposure levels for each job held were assigned to the study cohort using these standardized jobs by taking the arithmetic mean of all full-shift personal-noise samples available for each job. Noise exposure was also categorized as $<82$ (ie, effectively non-noise exposed), 82-84.99 (ie, low exposure), 85-87.99 (ie, moderate overexposure) and $\geq 88$ (ie, high overexposure) dBA. A trend analysis of noise sampling by plant-job from 2003-2008 was conducted to determine any changes in noise exposure over time.

The study company requires enrollment of workers in hearing conservation programs in areas where $\geq 5 \%$ of the noise measurement samples equal or exceed an 8 -hour time-weighted average of $82 \mathrm{dBA}$. Consequently, some workers who receive periodic audiometric testing work in areas where the median of ambient noise exposure measurements is $<82 \mathrm{dBA}$. Since 1978, certified audiometric technicians have conducted hearing tests for the frequencies $0.5,1,2,3,4,6,8 \mathrm{kHz}$ in test environments designed to meet the American National Standards Institute (ANSI) standards for industrial audiometry. Employee audiograms are maintained in a centralized electronic database accessible to the researchers under the data sharing arrangements described above. To define hearing impairment we used a criterion from the American Medical Association (AMA) Guide to the Evaluation of Permanent Impairment, which defines binaural hearing impairment as an average hearing threshold level across both ears $>25 \mathrm{~dB}$ for the frequencies of $0.51,2$, and $3 \mathrm{kHz}$ (41). We calculated HTL for each study year by taking the binaural average of hearing thresholds for the frequencies of $0.51,2$, and $3 \mathrm{kHz}$ from the audiometric test performed from 1 year before to 30 days after the beginning of each personyear contributed to the study period. Binaural hearing threshold levels were also categorized as: $<10$ (ie, normal hearing), 10-24.99 (ie, mild hearing loss) or $\geq 25$ (ie, impaired hearing) dB. The study company requires workers exposed to noise $>82 \mathrm{dBA}$ to wear hearing protection. The company's audiometric surveillance database frequently includes type of HPD used by the worker undergoing audiometric testing; however, no information regarding frequency or consistency of HPD use was available. To determine whether type of HPD used was a significant predictor of injury risk for the cohort, we categorized HPD type as plug, muff, canal cap, muff and plug, none, or unknown.

The job demand database contains an overall rating of physical job demand for each production or maintenance job at the six plant locations and has been described previously (38). For purposes of this study, physical demand ratings were dichotomized into heavy/ very heavy or light/medium.

\section{Subject selection criteria}

To be included in the study cohort, a worker must have worked between 1 January 2003 and 31 December 2008 in a job for which physical demand was rated and have had an audiogram performed from 1 year before to 30 days after the start of each person-year contributed. An encrypted uniform unique identifier was created for each employee to ensure human subject privacy and link databases. Figure 1 graphically displays the study cohort construction.

\section{Statistical methods}

Descriptive analysis of demographic characteristics for the cohort and distribution of noise exposure, injury, HTL, and HPD usage and tenure at baseline was performed. We calculated unadjusted injury and serious injury rates per 100 person years for each noise and HTL category by dividing the number of injury events by the summed number of person years for each injury outcome. We then used generalized linear mixed models to estimate relative risks (RR) for injury along with corresponding 95\% confidence intervals $(95 \% \mathrm{CI})$ for noise exposure category $(<82,82-84.99,85-87.99$, or $\geq 88 \mathrm{dBA})$ with $<82 \mathrm{dBA}$ as the referent and HTL $(<10,10-24.99, \geq 25 \mathrm{~dB})$ with $<10$ $\mathrm{dB}$ as the referent in multivariate models also adjusted for sex, age, race/ethnicity, tenure, physical job demand, HPD type, and calendar year to account for any temporal trend in injury risk during the study period. Because of the non-linear effect of year, we included year as a categorical variable. Age and tenure were highly correlated and colinear among the study cohort. Consequently, age, but not tenure was retained in the final statistical models. Tenure $<1$ year (yes/no), previously associated with increased injury risk in similar cohorts, (40) was included in the final models to adjust for any increased injury risk associated with inexperience or unfamiliarity with job tasks. For the acute injury outcome that included minor events, 


\begin{tabular}{|c|}
\hline Hourly workers at 6 manufacturing plants (Human Resources database) \\
\hline $\mathrm{n}=9,920$ persons \\
\hline Standardized Job Category available for job? \\
\hline Yes \\
\hline $\begin{array}{c}\text { • include in cohort (9,720 persons, 38,886 person-yrs) } \\
\text { Noise exposure available for Standardized Job Category ? (Industrial Hygiene database) }\end{array}$ \\
\hline Yes \\
\hline $\begin{array}{l}\text {-include in cohort \& determine avg noise exposure level } \\
\text { from samples }(9,479 \text { persons, } 37,255 \text { person-years) }\end{array}$ \\
\hline Physical Demand Rating available for job? (Job Demand database) \\
\hline Yes \\
\hline $\begin{array}{l}\text { • include in cohort (9,449 persons, 37,029 person-years) } \\
\text { Audiogram available for person within } 1 \text { year before to } \mathbf{3 0} \text { days after study year? (Audiometric Surveillance database) }\end{array}$ \\
\hline Yes \\
\hline - include in cohort (9,220 persons, 33,300 person-years) \\
\hline 9,220 persons $(13,323$ person-jobs), 33,300 person-years \\
\hline
\end{tabular}

Figure 1. Construction of Study Cohort. we chose a Poisson distribution with a log link and offset of the log person-days contributed to each job for each year of the study. Because of the distribution of serious injuries among the cohort, we selected a binomial distribution with a logit link and the injury rate denominator for the serious injury outcome was the summed person time contributed to each job for each year of the study. Random intercepts for person-within-job, job-within-plant, and plant were incorporated to allow for between- and within-person, job and plant variation and account for correlation resulting from clustering. An unstructured covariance structure was specified (42). All P-values were two-sided and $\alpha<0.05$ was considered statistically significant. Interactions between noise exposure, HTL and HPD type were explored. In addition, we modeled noise exposure and HTL as continuous variables in separate multivariate generalized linear mixed models adjusted as described above. To investigate possible effects of type of hearing protection used, we performed a sub-analysis using the sub-cohort for whom information on HPD type was available.

All statistical analyses were performed with SAS version 9.3 (SAS Institute, Cary, NC, USA).

\section{Results}

Over the six-year study period at the six study plants, 9220 production and maintenance workers contributing 33300 person-years met the inclusion criteria (figure 1). Table 1 displays descriptive statistics for the study cohort at the start of the study period. Of these 9220 workers ( $89 \%$ of whom were male), 3370 workers in 3690 personjobs sustained 5566 acute injuries, including minor injuries and 1165 workers in 1189 person-jobs sustained 1289 serious acute injuries that resulted in medical treatment, work restrictions, or lost work time. Of the serious acute injuries, $45 \%$ required medical treatment, $50 \%$ required work restrictions and only $5 \%$ resulted in lost work time. The description of persons injured during the study period is shown in table 2. Table 3 displays the distribution of injury by noise exposure category, HTL category, and HPD type. Trend analysis of noise sampling by plant-job showed that average noise exposure changed significantly for only 5 of the 120 unique plant-jobs during the study period, representing 295 persons ( 765 person-years). The unadjusted injury and serious injury rates by noise exposure category and HTL are shown in table 4 . An increase in unadjusted serious injury rate with increasing ambient noise exposure category was observed.

The results of multivariate mixed-effects models with noise exposure and HTL modeled categorically as well as continuously are shown in table 5 for each injury outcome. In multivariate models - simultaneously adjusted for noise exposure category, HTL category, sex, race/ethnicity, age, tenure $<1$ year, physical demands, HPD type, calendar year, and random intercepts for plant, job and person-within-plant-job - ambient noise exposure was associated with injury risk in a monotonic dose-dependent fashion for both injury outcomes examined, while HTL was associated with risk for all acute injury but was not a predictor of serious injury risk. 
Table 1. Descriptive statistics of covariates for cohort, at baseline. [SD=standard deviation; $\mathrm{dBA}=\mathrm{A}$-weighted decibels; $\mathrm{dB}=$ decibels ]

\begin{tabular}{lrrrr}
\hline & $\mathrm{N}$ & $\%$ & Mean & $\mathrm{SD}$ \\
\cline { 2 - 5 } Total & 9220 & 100 &. &. \\
Male & 8231 & 89 &. &. \\
Age at baseline (years) &. &. & 44.2 & 10.5 \\
Tenure at baseline (years) &. &. & 17.1 & 12.4 \\
White & 8069 & 87 &. &. \\
Mean noise exposure (dBA) &. &. &. &. \\
$<82$ & 4415 & 48 &. &. \\
$82-84.99$ & 2383 & 26 &. &. \\
$85-87.99$ & 1797 & 19 &. &. \\
$\geq 88$ & 625 & 7 &. &. \\
Hearing threshold level (average 0.5, &. &. &. &. \\
1, 2, 3 kHz) (dB) & & & & \\
$<10$ & 4432 & 48 &. &. \\
$10-24.99$ & 3828 & 42 &. &. \\
$\geq 25$ & 960 & 10 &. &. \\
Heavy/very heavy physical demands & 1603 & 17 &. &. \\
Hearing protective device & & & & \\
Plugs & 4420 & 48 &. &. \\
Canal caps & 549 & 6 &. &. \\
Muffs & 121 & 1 &. &. \\
Muff plus plugs & 867 & 9 &. &. \\
Unknown type & 3229 & 35 &. &. \\
None & 34 & 0.4 &. &. \\
\hline
\end{tabular}

Table 2. Descriptive statistics for persons injured, 2003-2008. [SD=standard deviation]

\begin{tabular}{|c|c|c|c|c|c|c|c|c|}
\hline & \multicolumn{4}{|c|}{ All acute injury } & \multicolumn{4}{|c|}{ Serious a acute injury } \\
\hline & $\mathrm{N}$ & $\%$ & Mean & SD & $\mathrm{N}$ & $\%$ & Mean & SD \\
\hline $\begin{array}{l}\text { Persons who } \\
\text { sustained } \\
\text { injuries }\end{array}$ & 3370 & 100 & . & & 1165 & 100 & $\cdot$ & . \\
\hline $\begin{array}{l}\text { Age at injury, } \\
\text { years }\end{array}$ & . & . & 44.5 & 10.4 & . & . & 45.0 & 10.0 \\
\hline Male & 2920 & 87 & . & 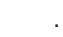 & 1020 & 87 & $\cdot$ & . \\
\hline White & 2934 & 87 & . & 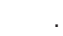 & 1004 & 86 & . & . \\
\hline
\end{tabular}

${ }^{a}$ Resulting in medical treatment, work restrictions, or lost work time.

Compared to those exposed to average noise levels $<82 \mathrm{dBA}$, workers exposed to average noise levels 82-84.99 dBA showed non-statistically significant increases in injury risk (15\% increase) and serious injury risk (26\% increase) (table 5). Workers in higher exposure categories all had significantly increased injury risk. Those exposed to average noise levels $85-87.99$ $\mathrm{dBA}$ had a $34 \%$ increase in risk of injury (RR 1.34, 95\% CI $1.07-1.70$ ) and a $39 \%$ increased serious injury risk (RR 1.39, 95\% CI 1.05-1.85). Workers exposed to noise $\geq 88 \mathrm{dBA}$ showed the greatest increase in injury (RR $1.61,95 \%$ CI 1.13-2.30) and serious injury (RR 2.29, 95\% CI 1.52-3.47) risk. Increasing age was associated with decreasing injury (RR $0.99,95 \%$ CI $0.98-0.99$ ) and serious injury (RR $0.99,95 \%$ CI $0.98-1.00$ ) risk. Female sex was associated with increased injury (RR 1.63, 95\% CI 1.51-1.77) and serious injury (RR 1.46, 95\%
Table 3. Distribution of acute injury by noise exposure, hearing threshold level, hearing protection device, and physical demand category, 2003-2008. [dBA=A-weighted decibels; $d B=d e c i b e l]$

\begin{tabular}{|c|c|c|c|c|}
\hline & \multicolumn{2}{|c|}{$\begin{array}{c}\text { All } \\
\text { acute injury } \\
\end{array}$} & \multicolumn{2}{|c|}{$\begin{array}{l}\text { Serious a } \\
\text { acute injury }\end{array}$} \\
\hline & $\mathrm{N}$ & $\%$ & $\mathrm{~N}$ & $\%$ \\
\hline Total injuries & 5566 & 100 & 1289 & 100 \\
\hline $\begin{array}{l}\text { Persons-jobs in which injuries } \\
\text { occurred }\end{array}$ & 3690 & 100 & 1189 & 100 \\
\hline \multicolumn{5}{|l|}{ Noise exposure (mean dBA) } \\
\hline$<82$ & 1717 & 47 & 503 & 42 \\
\hline $82-84.99$ & 804 & 22 & 278 & 23 \\
\hline $85-87.99$ & 920 & 25 & 289 & 24 \\
\hline$\geq 88$ & 249 & 7 & 119 & 10 \\
\hline \multicolumn{5}{|l|}{ HTL (average $0.5,1,2,3 \mathrm{kHz})(\mathrm{dB})$} \\
\hline$<10$ & 1864 & 50 & 582 & 49 \\
\hline $10-24.99$ & 1469 & 40 & 480 & 40 \\
\hline$\geq 25$ & 357 & 10 & 127 & 11 \\
\hline Heavy/very heavy physical demands & 668 & 18 & 212 & 18 \\
\hline \multicolumn{5}{|l|}{ Hearing protection device } \\
\hline Plugs & 3124 & 56 & 684 & 53 \\
\hline Canal caps & 262 & 5 & 66 & 5 \\
\hline Muffs & 78 & 1 & 13 & 1 \\
\hline Muff plus plugs & 537 & 10 & 131 & 10 \\
\hline Unknown type & 1561 & 28 & 395 & 31 \\
\hline None & 4 & 0.1 & 0 & 0 \\
\hline
\end{tabular}

${ }^{\text {a }}$ Resulting in medical treatment, work restrictions, or lost work time.

CI 1.24-1.72) risk. Tenure $<1$ year predicted all injury risk (RR $1.29,95 \%$ CI $1.15-1.44$ ) but not serious injury among the study cohort. Heavy physical demands were associated with increased risk for serious injury (RR $1.40,95 \%$ CI 1.04-1.89) and white race was associated with decreased risk of all acute injuries (RR $0.88,95 \%$ CI 0.81-0.96).

Considering the association between HTL and all injury risk, workers with HTL $>10 \mathrm{~dB}$ had increased risk for injury compared to workers with HTL $<10 \mathrm{~dB}$, and the magnitude of injury risk increased with increasing HTL category. Workers with HTL between 10-24.99 dB showed a $6 \%$ increase in injury risk (RR $1.06,95 \% \mathrm{CI}$ $1.00-1.13$ ) while those with HTL $\geq 25 \mathrm{~dB}$ displayed a $21 \%$ increase in risk of injury (RR 1.21, 95\% CI 1.09-1.33). Type of HPD was not a significant predictor of injury risk in this cohort. No significant interactions between ambient noise exposure, HTL, and HPD type were observed.

Modeling mean ambient noise exposure and HTL as continuous variables using multivariate mixed models described above showed that for each $5 \mathrm{dBA}$ increase in mean noise exposure, the risk of injury increased by $21 \%$ (RR $1.21,95 \%$ CI $1.10-1.33$ ), while the risk of serious injury increased by $26 \%$ (RR $1.26,95 \%$ CI 1.11-1.43). For each $5 \mathrm{~dB}$ increase in HTL, the risk of injury increased by $3 \%$ (RR 1.03, 95\% CI 1.02-1.05), but the risk of serious injury was unchanged.

The results from the sub-analyses, conducted on the sub-cohort for whom HPD type was available, showed that HPD type did not appreciably change the estimates 
Table 4. Unadjusted all injury and serious injury rates per 100 person-years by noise exposure and hearing threshold level, 2003-2008. [ $\mathrm{dBA}=\mathrm{A}$-weighted decibels; $\mathrm{dB}=$ decibel]

\begin{tabular}{lrrrrr}
\hline & \multicolumn{2}{c}{ All acute injury } & & \multicolumn{2}{c}{ Serious a acute injury } \\
\cline { 2 - 3 } \cline { 5 - 6 } & $\mathrm{N}$ & Rate & & $\mathrm{N}$ & Rate \\
\cline { 2 - 3 } Total & 5566 & 16.71 & & 1289 & 3.87 \\
Mean noise exposure (dBA) & & & & \\
$\quad<82$ & 2674 & 16.39 & & 543 & 3.33 \\
$82-84.99$ & 1189 & 14.82 & 299 & 3.73 \\
$85-87.99$ & 1327 & 19.62 & 314 & 4.64 \\
$\geq 88$ & 376 & 17.07 & 133 & 6.04 \\
Hearing threshold level (dB) & & & & \\
$<10$ & 2723 & 17.30 & 628 & 3.99 \\
10-24.99 & 2218 & 15.91 & 524 & 3.76 \\
$\geq 25$ & 625 & 17.25 & 137 & 3.78 \\
\hline
\end{tabular}

a Resulting in medical treatment, work restrictions, or lost work time.

for noise exposure or HTL (data not shown). Moreover, difference in HPD type used was not a significant predictor of injury $(\operatorname{Pr}>\mathrm{F}=0.2874)$ or serious injury $(\operatorname{Pr}>\mathrm{F}=0.2707)$.

\section{Discussion}

Our study adds to existing evidence that ambient occupational noise exposure may increase injury risk in an exposure-response pattern. Using generalized linear mixed models with random effects for plant, job-withinplant and person-within-job, and adjusting for other known predictors of injury risk as well as potential confounders, we show that average noise exposure as low as $85 \mathrm{dBA}$ may elevate injury risk and this association appears independent of job-specific injury risk. In partial support of a previous report, which demonstrated a dose-dependent increase in injury risk with hearing loss (28), our findings show a monotonic increase in all injury risk with increasing HTL. At the same time, we found no association between hearing threshold levels and serious injury risk among our study cohort.

Contrary to a previous report suggesting that workers with hearing loss (HTL $>20 \mathrm{~dB})$ were at reduced risk for injury associated with occupational noise exposure $>82$ $\mathrm{dBA}(25)$, results from our models suggest that workers with hearing loss ( $\mathrm{HTL} \geq 25 \mathrm{~dB}$ ) may be at greater risk for injury associated with ambient noise exposures than individuals without hearing impairment. However, further study is needed to confirm or refute the association suggested by our results and to examine associations between higher frequency hearing acuity and injury risk given that previous reports calculated hearing loss using HTL at a variety of frequencies.

While we have insufficient information to ascertain the mechanism by which ambient noise exposure or hear- ing acuity may increase injury risk in our cohort, HPD type did not impact the observed associations, suggesting that situational awareness may be negatively influenced by a combination of auditory and extra-auditory effects of noise exposure. Further investigation is warranted.

Previous research has reported increased injury risk with workplace noise exposure $\geq 90 \mathrm{~dB}(27,28)$ and $>85$ dBA (6), as well dose-response relationships between hearing loss and accident risk (28) and between noise exposure and injury risk for workers with HTL $\leq 20 \mathrm{~dB}$ (25). Conversely, a recent study of noise exposure and serious injuries among sawmill workers reported a lack of a dose-response relationship between noise exposure and injury risk (43), findings possibly influenced by the study's inability to control for hearing level and job-specific degree of hazard. Our study findings document evidence of a dose-response relationship between ambient workplace noise exposure and injury risk, controlling for HTL, with more than a two-fold increase in serious injury risk for average noise exposures $\geq 88 \mathrm{dBA}$.

Consistent with previous studies of worker cohorts from the company studied here, female sex and younger age were each associated with elevated injury risk, and heavy physical demand predicted serious injury risk but did not achieve statistical significance in predicting all injury risk (38-40). Tenure $<1$ year was associated with increasing risk for the outcome that included minor injuries as reported previously (40) but did not attain statistical significance in predicting more serious acute injury among the study cohort. Recognizing that injury risk varies by job for reasons unrelated to noise exposure or physical demand, job was modeled as a random effect to control for confounding by unmeasured job effects. Interestingly in this cohort, noise exposure and physical demand, used as a surrogate for degree of hazard, were poorly correlated $(\mathrm{r}=0.05)$, suggesting that noise exposure contributes to injury risk independent of the hazardous nature of the job.

Hearing loss in this cohort was calculated regardless of attribution to occupational or non-occupational exposures. This distinction is important since hearing loss can arise from either or both sources of exposure to hazardous noise as well as from other causes. While hearing loss source apportionment is important for the purposes of workers' compensation, the degree of hearing loss, and not the source, was critical for our study, and our results provide additional evidence that ambient noise exposure may increase injury risk regardless of hearing acuity.

There are some limitations to this study. First, we had no ability to ascertain the "in ear" or tympanic membrane noise exposure for our cohort to determine the actual noise exposures that workers were experiencing as well as the actual protection being provided by hearing protective devices. Despite availability of HPD type information for roughly $65 \%$ of our cohort, HPD fit and usage 
Table 5. Fully adjusted multivariate mixed model results with random intercepts for plant, job and person within plant-job. [RR=relative risk; 95\% $\mathrm{Cl}=95 \%$ confidence interval; $\mathrm{Pr}>\mathrm{F}=$ significance test for fixed effects; $\mathrm{HTL}=$ hearing threshold level; $d B A=A$-weighted decibels; $d B=d e c i b e l]$

\begin{tabular}{|c|c|c|c|c|c|c|}
\hline & \multicolumn{3}{|c|}{ Acute injury (including minor injuries) } & \multicolumn{3}{|c|}{ Serious ${ }^{\text {a }}$ acute injury } \\
\hline & $\mathrm{RR}{ }^{\mathrm{b}}$ & $95 \% \mathrm{Cl}$ & $\operatorname{Pr}>\mathrm{F}$ & $\mathrm{RR} b$ & $95 \% \mathrm{Cl}$ & $\operatorname{Pr}>\mathrm{F}$ \\
\hline \multicolumn{7}{|l|}{ Noise and HTL modeled as categorical variables } \\
\hline Noise (mean dBA) & & Reference & 0.0135 & & Reference & 0.0005 \\
\hline$<82$ & 1.00 & & & 1.00 & & \\
\hline $82-84.99$ & 1.15 & $0.94-1.41$ & & 1.26 & $0.96-1.64$ & \\
\hline $85-87.99$ & 1.34 & $1.07-1.70$ & & 1.39 & $1.05-1.85$ & \\
\hline$\geq 88$ & 1.61 & $1.13-2.30$ & & 2.29 & $1.52-3.47$ & \\
\hline$\overline{\mathrm{HTL}}$ (average 0.5,1, 2, $3 \mathrm{kHz})(\mathrm{dB})$ & & Reference & 0.0008 & & Reference & 0.2751 \\
\hline$<10$ & 1.00 & & & 1.00 & & \\
\hline $10-24.99$ & 1.06 & $1.00-1.13$ & & 1.07 & $0.94-1.20$ & \\
\hline$\geq 25$ & 1.21 & $1.09-1.33$ & & 1.17 & $0.96-1.42$ & \\
\hline Age (each 1 year increase) & 0.99 & $0.98-0.99$ & $<0.0001$ & 0.99 & $0.98,1.00$ & 0.0038 \\
\hline Female & 1.63 & $1.51-1.77$ & $<0.0001$ & 1.46 & $1.24-1.72$ & $<0.0001$ \\
\hline Heavy/very heavy physical demands & 1.16 & $0.90-1.50$ & 0.2427 & 1.40 & $1.04-1.89$ & 0.0274 \\
\hline Tenure $<1$ year & 1.29 & $1.15-1.44$ & $<0.0001$ & 1.07 & $0.84-1.36$ & 0.5796 \\
\hline White & 0.88 & $0.81-0.96$ & 0.0026 & 0.96 & $0.82-1.13$ & 0.6486 \\
\hline \multicolumn{7}{|l|}{ Noise and HTL modeled as continuous variables } \\
\hline Mean noise exposure (each $5 \mathrm{dBA}$ increase) & 1.21 & $1.10-1.33$ & $<0.0001$ & 1.26 & $1.11-1.43$ & 0.0003 \\
\hline HTL (average 0.5,1, 2, $3 \mathrm{kHz}$ ) (each $5 \mathrm{~dB}$ increase) & 1.03 & $1.02-1.05$ & $<0.0001$ & 1.03 & $0.99-1.06$ & 0.1048 \\
\hline Age (each 1-year increase) & 0.99 & $0.98-0.99$ & $<0.0001$ & 0.99 & $0.98,1.00$ & 0.0037 \\
\hline Female & 1.64 & $1.51-1.77$ & $<0.0001$ & 1.46 & $1.24-1.72$ & $<0.0001$ \\
\hline Heavy/very heavy physical demands & 1.19 & $0.93-1.52$ & 0.1667 & 1.42 & $1.05-1.92$ & 0.0245 \\
\hline Tenure $<1$ year & 1.29 & $1.16-1.44$ & $<0.0001$ & 1.07 & $0.84-1.37$ & 0.5567 \\
\hline White & 0.88 & $0.81-0.95$ & 0.0020 & 0.96 & $0.81-1.13$ & 0.6138 \\
\hline
\end{tabular}

a Resulting in medical treatment, work restrictions or lost work time.

${ }^{\mathrm{b}}$ Adjusted for noise exposure, hearing threshold level, hearing protector type, sex, age, physical demand, race/ethnicity, tenure $<1$ year, calendar year and for random effects of plant, job, and person-within-plant-job.

patterns likely vary widely within our cohort and could impact true noise reduction achieved with HPD usage. Second, we have not accounted for the variable number of hours worked across individual workers or the effect of overtime, another recognized risk for injury (44). To determine whether variance in hours worked represented a confounder of concern, we conducted a sub-analysis using data from the three plants for which actual hours worked was available during the study period. RR from this sub-analysis (data not shown) were very similar to our reported results, leading us to conclude that no major confounding by variation in actual hours worked exists. A third limitation was the use of only one metric (AMA hearing impairment) and set of audiometric frequencies to define hearing loss. Our choice of frequencies was based on their importance in speech communication, but future studies should explore the association between hearing loss at other frequencies and injury risk.

The above limitations notwithstanding, this study has several strengths. The large study cohort and wealth of available data allowed reconstruction of complete worker job and injury histories, accurate determination of HTL for each person-year contributed, and objective assignment of average noise exposure for each job held, which obviated any need to rely on self-reported data. Further, these rich data allowed us to control for a number of covariates recognized as contributing to injury risk (38-
40), thus increasing accuracy of RR estimates attributed to HTL and noise exposure for the study cohort. In addition, our modeling of random effects for job-within-plant, and person-within-job to account for correlation among clustered variables and repeated measures on persons provides increased confidence in study results.

Some evidence exists that noise may increase injury risk, particularly for falls, through changes in postural sway amplitude and center of pressure variability (31). Future analyses will examine differential effects of noise exposure and/or HTL on specific incident types, eg, falls, struck by equipment/machinery, etc, adding additional years of data to provide sufficient statistical power to discern meaningful associations. Additionally, the relative contribution of hearing acuity at higher frequencies and lower frequencies to acute injury risk warrants further examination. A final area for future investigation is the effect of HTL and HPD use on workers' ability to communicate effectively, hear warning signals or machine noise, and have sufficient awareness of their work environment under workplace noise exposure levels $\geq 85 \mathrm{dBA}$.

\section{Concluding remarks}

Our findings, in conjunction with previous reports, highlight the importance of reducing ambient noise 
exposure through engineering controls, regardless of the precise mechanism(s) through which noise exposure impacts injury risk, and carefully examining the communication needs of hearing-impaired workers exposed to workplace noise. Moreover, our study suggests that noise levels equivalent to those found in many nonoccupational environments may contribute to injury risk, which has implications for the population at large and is deserving of further investigation.

\section{Acknowledgments}

This research was funded by grants from the National Institute on Aging (Disease, Disability and Death in an Aging Workforce, NIH/NIA, 1 R01 AG026291-06), National Institute for Occupational Health and Safety (Assessing hearing conservation effectiveness, 1 R01 OH010132-01), and a contract with Alcoa Inc.

\section{Competing interests}

Cantley, Galusha, Rabinowitz, and Cullen receive a portion of their compensation at Yale and Stanford through a long-standing contractual agreement with Alcoa, Inc. Dixon-Ernst was employed by Alcoa, Inc during the time this work was conducted.

\section{Data sharing}

As an alternative to providing a de-identified data set to the public domain, we allow access for the purpose of re-analyses or appropriate "follow-on" analyses by any qualified investigator willing to sign a contractual covenant with the host Institution limiting use of data to a specific agreed upon purpose and observing the same restrictions as are limited in our contract with Alcoa, such as 60-day manuscript review for compliance purposes.

\section{References}

1. Tak S, Davis RR, Calvert GM. Exposure to hazardous workplace noise and use of hearing protection devices among US workers-NHANES, 1999-2004. Am J Ind Med. 2009;52(5):358-71. http://dx.doi.org/10.1002/ajim.20690.

2. Hammer MS, Swinburn TK, Neitzel RL. Environmental noise pollution in the United States:developing an effective public health response. [Erratum appears in Environ Health Perspect. 2014 Feb;122(2):118]. Environ Health Perspect. 2014;122(2):115-9.

3. Passchier-Vermeer W, Passchier WF. Noise exposure and public health. Environ Health Perspect.2000;108 Suppl 1:123-31. http://dx.doi.org/10.1289/ehp.00108s1123.

4. Collee A, Legrand C, Govaerts B, Van Der Veken P, De Boodt F, Degrave E. Occupational exposure to noise and the prevalence of hearing loss in a Belgian military population: a cross-sectional study. Noise Health. 2011;13(50):64-70. http:// dx.doi.org/10.4103/1463-1741.73997.

5. Mihailovic A, Grujic SD, Kiurski J, Krstic J, Oros I, Kovacevic I. Occupational noise in printing companies. Environ Monit Assess. 2011;181(1-4):111-22. http://dx.doi.org/10.1007/ s10661-010-1817-5.

6. Amjad-Sardrudi H, Dormohammadi A, Golmohammadi R, Poorolajal J. Effect of Noise Exposure on Occupational Injuries: A Cross-sectional Study. J Res Health Sci. 2012;12(2):101-4.

7. Morata TC, Themann CL, Randolph RF, Verbsky BL, Byrne DC, Reeves ER. Working in noise with a hearing loss: perceptions from workers, supervisors, and hearing conservation program managers. Ear Hear. 2005;26(6):52945. http://dx.doi.org/10.1097/01.aud.0000188148.97046.b8.

8. Nelson DI, Nelson RY, Concha-Barrientos M, Fingerhut M. The global burden of occupational noise-induced hearing loss. Am J Ind Med. 2005;48(6):446-58. http://dx.doi.org/10.1002/ ajim.20223.

9. WHO. The World Health Report 2002: Reducing Risks, Promoting Healthy Life. Geneva: 2002.

10. Suter A. Standards and Regulations. In: Berger E, Royster L, Driscoll D, Layne M, editors. The Noise Manual. 5th ed. Fairfax, VA: American Industrial Hygiene Association; 2000.

11. Ward W, Royster J, Royster L. Auditory and Non-Auditory Effects of Noise. In: Berger E, Royster L, Royster J, Driscoll D, Layne M, editors. The Noise Manual. 5th ed. Fairfax, VA: American Industrial Hygiene Association; 2000. p. 123-47.

12. Rosler G. Progression of hearing loss caused by occupational noise. Scand Audiol. 1994;23(1):13-37. http://dx.doi. org/10.3109/01050399409047483.

13. Leather P, Beale D, Sullivan L. Noise, psychosocial stress and their interaction in the workplace. J Environ Psychol. 2003;23(2):213-22. http://dx.doi.org/10.1016/S02724944(02)00082-8.

14. Jahncke H, Halin N. Performance, fatigue and stress in openplan offices: the effects of noise and restoration on hearing impaired and normal hearing individuals. Noise Health. 2012;14(60):260-72. http://dx.doi.org/10.4103/14631741.102966 .

15. Muzammil M, Khan AA, Hasan F, Hasan SN. Effect of noise on human performance under variable load in a die casting industry--a case study. J Environ Sci Eng. 2004;46(1):49-54.

16. Kumar UA, Ameenudin S, Sangamanatha AV. Temporal and speech processing skills in normal hearing individuals exposed to occupational noise. Noise Health. 2012;14(58):100-5.

17. Gitanjali B, Ananth R. Effect of acute exposure to loud occupational noise during daytime on the nocturnal sleep architecture, heart rate, and cortisol secretion in healthy volunteers. J Occup Health. 2003;45(3):146-52. http://dx.doi. org/10.1539/joh.45.146. 
18. Attarchi M, Dehghan F, Safakhah F, Nojomi M, Mohammadi S. Effect of exposure to occupational noise and shift working on blood pressure in rubber manufacturing company workers. Ind Health. 2012;50(3):205-13. http://dx.doi.org/10.2486/ indhealth.MS1321.

19. Bortkiewicz A, Gadzicka E, Siedlecka J, Szyjkowska A, Viebig P, Wranicz JK, et al. Work-related risk factors of myocardial infarction. Int J Occup Med Environ Health. 2010;23(3):25565. http://dx.doi.org/10.2478/v10001-010-0030-7.

20. Gan WQ, Davies HW, Demers PA. Exposure to occupational noise and cardiovascular disease in the United States: the National Health and Nutrition Examination Survey 19992004. Occup Environ Med. 2011;68(3):183-90. http://dx.doi. org/10.1136/oem.2010.055269.

21. NIOSH. National Occupational Research Agenda. DHHS (NIOSH) Publication No 96-115. 1996.

22. Prince MM, Stayner LT, Smith RJ, Gilbert SJ. A reexamination of risk estimates from the NIOSH Occupational Noise and Hearing Survey (ONHS). J Acoust Soc Am. 1997;101(2):950-63. http://dx.doi.org/10.1121/1.418053.

23. Nelson DI, Concha-Barrientos M, Driscoll T, Steenland K, Fingerhut M, Punnett L, et al. The global burden of selected occupational diseases and injury risks: Methodology and summary. Am J Ind Med. 2005;48(6):400-18. http://dx.doi. $\operatorname{org} / 10.1002 /$ ajim.20211.

24. Leigh JP. Economic burden of occupational injury and illness in the United States. Milbank Q. 2011;89(4):728-72. http:// dx.doi.org/10.1111/j.1468-0009.2011.00648.x.

25. Moll van Charante AW, Mulder PGH. Perceptual Acuity and the Risk of Industrial Accidents. Am J Epidemiol. 1990;131(4):652-63.

26. Wilkins PA, Action WI. Noise and accidents--a review. Ann Occup Hyg. 1982;25(3):249-60. http://dx.doi.org/10.1093/ annhyg/25.3.249.

27. Picard M, Girard SA, Simard M, Larocque R, Leroux T, Turcotte F. Association of work-related accidents with noise exposure in the workplace and noise-induced hearing loss based on the experience of some 240,000 person-years of observation. Accid Anal Prev. 2008;40(5):1644-52. http:// dx.doi.org/10.1016/j.aap.2008.05.013.

28. Girard SA, Picard M, Davis AC, Simard M, Larocque R, Leroux T, et al. Multiple work-related accidents: tracing the role of hearing status and noise exposure. Occup Environ Med. 2009;66(5):319-24. http://dx.doi.org/10.1136/ oem.2007.037713.

29. Smith A. Noise, performance efficiency and safety. Int Arch Occup Environ Health. 1990;62(1):1-5. http://dx.doi. org/10.1007/BF00397841.

30. Kjellberg A, Muhr P, Skoldstrom B. Fatigue after work in noise - an epidemiological survey study and three quasiexperimental field studies. Noise Health. 1998;1(1):47-55.

31. Park S, Lee K, Lockhart T, Kim S. Effects of Sound on Postural Stability during Quiet Standing. J Neuroeng Rehabil. 2011;8(1):67. http://dx.doi.org/10.1186/1743-0003-8-67.

32. Choi S-W, Peek-Asa C, Sprince NL, Rautiainen RH, Donham
KJ, Flamme GA, et al. Hearing loss as a risk factor for agricultural injuries. Am J Ind Med. 2005;48(4):293-301. http://dx.doi.org/10.1002/ajim.20214.

33. Hockey GR. Compensatory control in the regulation of human performance under stress and high workload; a cognitiveenergetical framework. Biol Psychol. 1997;45(1-3):73-93. http://dx.doi.org/10.1016/S0301-0511(96)05223-4.

34. Jones DM, Macken WJ. Irrelevant tones produce an irrelevant speech effect: Implications for phonological coding in working memory. J Exp Psychol Learn Mem Cog. 1993;19(2):369-81. http://dx.doi.org/10.1037/0278-7393.19.2.369.

35. Szalma JL, Hancock PA. Noise effects on human performance: a meta-analytic synthesis. Psychol Bull. 2011;137(4):682-707. http://dx.doi.org/10.1037/a0023987.

36. Dias A, Cordeiro R. Fraction of work-related accidents attributable to occupational noise in the city of Botucatu, Sao Paulo, Brazil. Noise Health. 2008;10(40):69-73. http://dx.doi. org/10.4103/1463-1741.44344.

37. Zwerling C, Sprince NL, Wallace RB, Davis CS, Whitten PS, Heeringa SG. Risk factors for occupational injuries among older workers: an analysis of the health and retirement study. Am J Public Health. 1996;86(9):1306-9. http://dx.doi. org/10.2105/AJPH.86.9.1306.

38. Pollack KM, Agnew J, Slade MD, Cantley L, Taiwo O, Vegso $\mathrm{S}$, et al. Use of employer administrative databases to identify systematic causes of injury in aluminum manufacturing. Am J Ind Med. 2007;50(9):676-86. http://dx.doi.org/10.1002/ ajim. 20493.

39. Taiwo OA, Cantley LF, Slade MD, Pollack KM, Vegso $\mathrm{S}$, Fiellin $\mathrm{MG}$, et al. Sex differences in injury patterns among workers in heavy manufacturing. Am J Epidemiol. 2009;169(2):161-6. http://dx.doi.org/10.1093/aje/kwn304.

40. Kubo J, Cullen MR, Cantley L, Slade M, Tessier-Sherman B, Taiwo O, et al. Piecewise exponential models to assess the influence of job-specific experience on the hazard of acute injury for hourly factory workers. BMC Med Res Methodol. 2013;13:89. http://dx.doi.org/10.1186/1471-2288-13-89.

41. Cocchiarella L, Andersson GBJ, editors. Guides to the evaluation of permanent impairment. 5th ed. Chicago: American Medical Association Press; 2001. p. 613.

42. Stroup W. Generalized Linear Mixed Models: Chapman and Hall; 2012.

43. Kling RN, Demers PA, Alamgir H, Davies HW. Noise exposure and serious injury to active sawmill workers in British Columbia. Occup Environ Med. 2012;69(3):211-6. http://dx.doi.org/10.1136/oem.2010.058107.

44. Vegso S, Cantley L, Slade M, Taiwo O, Sircar K, Rabinowitz P, et al. Extended work hours and risk of acute occupational injury: A case-crossover study of workers in manufacturing. Am J Ind Med. 2007;50(8):597-603. http:// dx.doi.org/10.1002/ajim.20486.

Received for publication: 2 April 2014 